\title{
ENSO Influence on Regional Atmospheric Circulation and Thermodynamics Over Northern South America
}

Melissa Ruiz-Vásquez ( $\sim$ mruiz@bgc-jena.mpg.de)

Max Planck Institute for Biogeochemistry: Max-Planck-Institut fur Biogeochemie https://orcid.org/0000-0001-9847-3399

\section{Paola A. Arias}

Universidad de Antioquia

\section{J. Alejandro Martínez}

Universidad de Antioquia

\section{Research Article}

Keywords: Atmospheric instability, El Nino, La Nina, atmospheric moisture transport, regional Hadley cell, relative humidity

Posted Date: November 15th, 2021

DOI: https://doi.org/10.21203/rs.3.rs-1072436/v1

License: (1) This work is licensed under a Creative Commons Attribution 4.0 International License. Read Full License 


\title{
ENSO influence on regional atmospheric
}

\author{
circulation and thermodynamics over
}

\section{Northern South America}

\author{
Melissa Ruiz-Vásquez ${ }^{1,2 *}$, Paola A. Arias ${ }^{1 \dagger}$ and J. Alejandro \\ Martínez $^{1 \dagger}$

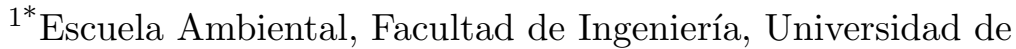 \\ Antioquia, Medellín, Antioquia, Colombia. \\ ${ }^{2}$ Now at Biogeochemical Integration, Max Planck Institute for \\ Biogeochemistry, Jena, Thüringen, Germany.
}
*Corresponding author(s). E-mail(s): melissa.ruiz1@udea.edu.co; Contributing authors: paola.arias@udea.edu.co; john.martinez@udea.edu.co;
$\dagger$ These authors contributed equally to this work.

\begin{abstract}
The interannual variability of hydroclimatic conditions in Northern South America (NOSA), specially precipitation, is mainly influenced by the El Niño-Southern Oscillation (ENSO). We explored potential mechanisms that affect precipitation occurrence in NOSA during El Niño and La Niña events over the period 1980-2019, using data from the ERA5 reanalysis. We looked at the atmospheric moisture contribution from different sources using the Dynamic Recycling Model to track water vapour trajectories. Interestingly, conditions with reduced precipitation during El Niño events can take place along with increased precipitable water. To understand this, we analyzed thermodynamic conditions in the atmosphere that are necessary for precipitation to occur over the region, such as convective available potential energy, convective inhibition, lifting condensation level and low-level relative humidity. With this approach, we found more favorable atmospheric conditions for the occurrence of precipitation during La Niña events, even if the
\end{abstract}


content of water vapor was equal or even less than during El Niño events. We also looked at the structure of the regional Hadley circulation in both types of events and found a weakening of the rising motion of the cell during El Niño, which further reduces convective processes over this region. This study provides an integral picture of how precipitation anomalies over NOSA during ENSO events are related both to thermodynamic conditions and sources of atmospheric moisture.

Keywords: Atmospheric instability, El Niño, La Niña, atmospheric moisture transport, regional Hadley cell, relative humidity

\section{Introduction}

El Niño Southern Oscillation (ENSO) is the main source of interannual hydroclimatic variability in Northern South America (NOSA) (Poveda et al, 2006; Córdoba-Machado et al, 2015; Shimizu et al, 2017; Cai et al, 2020; Arias et al, 2021). The positive phase of the ENSO, known as El Niño (EN), is associated with reduction in precipitation and increase in near-surface temperature over the region. By contrast, its counterpart or negative phase, known as La Niña (LN), is associated with an increase in precipitation and a reduction in near-surface temperatures (Poveda and Mesa, 1996; Wang, 2004; Capotondi et al, 2015; Salas et al, 2020). These changes in near-surface temperature associated with the ENSO phases modify the strength of winds (both easterlies and westerlies) that also explain precipitation differences in both EN and LN (Mesa-Sánchez and Rojo-Hernández, 2020). Despite of the tremendous efforts in studying this phenomenon, the mechanisms behind its effects at a regional and local scale are still being understood (Canchala et al, 2020; Yan et al, 2020; Bolaños et al, 2021; Cerón et al, 2021; Sori et al, 2021).

Several studies have addressed the effects of ENSO events in precipitation through the changes in atmospheric moisture contribution during both EN and LN events (Ropelewski and Halpert, 1989; Castillo et al, 2014; Llamedo 
et al, 2017; Sulca et al, 2018; Sori et al, 2021). Particularly for NOSA, Arias et al (2015) indicated that the anomalous wet season during the period 20102012 was mainly controlled by an enhanced moisture contribution from the Caribbean sea, the tropical Atlantic ocean and the eastern Pacific ocean. From another perspective, Hoyos et al (2019b) evaluated the spatio-temporal variability of atmospheric moisture in NOSA in seasonal and interannual time scales and emphasized in the role of the Intertropical Convergence Zoneinduced circulation and low-level jets as the most important sources for this variability. As a final example, Morales et al (2021) highlight the role of the low-level jets in moisture transport, for instance, in different ENSO regimes. They show that during LN, the low-level circulation over western Colombia, known as the Choco Jet (Poveda and Mesa, 1999, 2000), strengthens the wind shear over the region, a key mechanism in atmospheric moisture advection. These previous studies suggest that changes in precipitation in NOSA, during strong La Niña events for example, are characterized by an enhanced moisture transport of surrounding regions which is also associated to changes in regional circulation.

In comparison to the effects in atmospheric moisture contribution, less attention has been given to ENSO effects in thermodynamics over NOSA. Nevertheless, there are some studies that show the strong effect of thermodynamics in precipitation patterns over specific regions. Lintner and Boos (2019) explored the relationship between the South Pacific Convergence Zone (SPCZ) and ENSO events through a 2D approach of atmospheric energy transport. They showed that water and energy flux anomalies during ENSO dominate the SPCZ shift. Other study by Bayr et al (2021) quantified the thermodynamic feedbacks between the ocean and the atmosphere through sea surface 
temperatures (SSTs) and heat fluxes simulated by climate models. They suggest that the better representation of thermodynamic feedbacks between the ocean and the atmosphere, the more realistic simulation of ENSO events. This highlights the importance of thermodynamic processes as main drivers in the response of precipitation to ENSO events.

A supporting mechanism of these thermodynamic drivers is the Hadley cell (Ye et al, 1998). Riemann-Campe et al (2009) presented a global climatology of the thermodynamic indices Convective Available Potential Energy (CAPE) and Convective Inhibition (CIN). They show that large values of CAPE and CIN resemble the ascending and descending parts of the Hadley Cell, respectively. The Hadley cell also plays a role in the response of precipitation during ENSO events (Guo and Li, 2016). Kayano et al (2019) studied the regional circulation patterns in terms of the Walker and Hadley cells during LN events. They found that variations in both cells affect precipitation in South America during LN events due to an enhancement of the rising motions. For the EN events, it is the weakened rising motion and the strengthened downward motion of the Hadley cell which play the key roles. However, Rollings and Merlis (2021) found that the relationship between ENSO and the Hadley cell is strong only when considering low-frequency variability in the ENSO signal.

Following the importance of (i) atmospheric moisture advection, (ii) thermodynamic feedbacks and (iii) regional circulation patterns in response to ENSO events, we analyzed the effects of EN and LN in NOSA's precipitation and the main drivers behind. First, we quantified the atmospheric moisture contribution from different sources to NOSA (and the contribution of NOSA to itself, i.e. atmospheric moisture recycling). Second, we analyzed various thermodynamic parameters related to atmospheric instability and that are usually associated with the occurrence of precipitation. Third, we looked at the 
response of the regional Hadley cell in terms of the rising and sinking motions of air parcels. With the reasoning of these mechanisms we aimed to understand the mechanisms behind the influence of ENSO on precipitation over the NOSA region.

\section{Data and methodology}

\subsection{Study area}

We performed our analyses on the regional domain of tropical South America shown in Fig 1 . To study the atmospheric water vapour transport, we subdivided the domain in different subregions (sinks and sources of atmospheric moisture) following the approaches of Arias et al (2015), Agudelo et al (2019) and Ruiz-Vásquez et al (2020) of big continental basins and latitudinal classification of oceanic sources. We focused in the NOSA subregion as a sink of atmospheric moisture during the ENSO phases: EN and LN. Arias et al (2015) quantified the total water vapor contribution to NOSA from the considered sources. They account in approximately $79 \%$ of the total atmospheric moisture that reaches NOSA. The remaining $21 \%$ may be due to moisture unbalances depicted by the input atmospheric fields and additional losses in the numerical schemes of the DRM. 


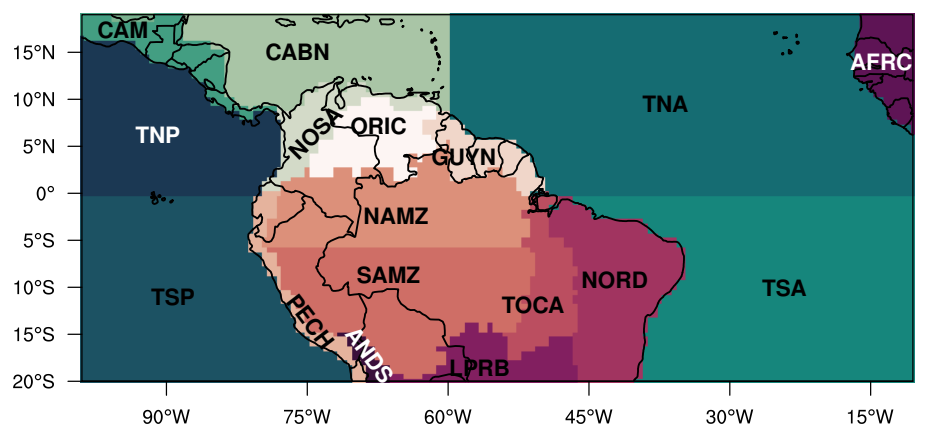

Fig. 1 Domain considered to estimate water vapor transport towards northern South America (NOSA) using the DRM. TNP: Tropical North Pacific, TSP: Tropical South Pacific, TNA: Tropical North Atlantic, TSA: Tropical South Atlantic, CAM: Central America, CABN: Caribbean Sea, ORIC: Orinoco basin, GUYN: Guyanas, PECH: Peru-Chile, NAMZ: Northern Amazon, SAMZ: Southern Amazon, TOCA: Tocantins basin, NORD: Brazilian Nordeste, LPRB: La Plata River Basin, AFRC: Africa, ANDS: Subtropical Andes

\subsection{ENSO events}

To select the periods corresponding to each ENSO event (EN and LN), we examined the Oceanic Niño Index (ONI) (Glantz and Ramirez, 2020). This index considers the SST anomalies of the tropical Pacific ocean averaged in the region $5^{\circ} \mathrm{N}-5^{\circ} \mathrm{S}, 170^{\circ} \mathrm{W}-120^{\circ} \mathrm{W}$ during the period $1980-2019$. For a season to be considered as part of an ENSO event, the SST anomalies (using a 3-month running mean) must exceed $\pm 0.5^{\circ} \mathrm{C}$ for at least five consecutive months. This is the operational definition used by the National Oceanic and Atmospheric Administration (NOAA). In the Appendix A, the Table A1 shows the seasons classified as EN (red) and LN (blue) events during the period 1980-2019.

We focused our analyses only on the differences in atmospheric and thermodynamic-related variables between EN and LN events that are statistically significant according to a Bootstrap test (Efron, 1992). For this purpose, 
1000 iterations were carried out with a statistical significance threshold of $95 \%$ for each variable (Agudelo et al, 2019).

\subsection{Atmospheric moisture sources}

We used the DRM to track the atmospheric humidity from source to sink regions during ENSO events. Particularly, NOSA is the sink region of interest in this study. The DRM is a 2D analytical model that uses a semi-Lagrangian approach to estimate the spatio-temporal variation of the atmospheric moisture that is recycled in a target region (i.e., that originates as evapotranspiration in the same region) and is advected to and from other remote regions (Dominguez et al, 2006; Martínez and Dominguez, 2014; Ruiz-Vásquez et al, 2020). The model is derived from the water vapor conservation equation integrated into the atmosphere (Eq. 1) and can be used for time scales from days (being the storage term important in the conservation of water vapor) to monthly and larger scales (Dominguez et al, 2006).

$$
\begin{gathered}
\frac{\partial(W)}{\partial t}+\frac{\partial(W U)}{\partial x}+\frac{\partial(W V)}{\partial y}=E-P \\
W=\int_{0}^{p_{0}} \bar{q} \frac{d p}{g} \\
U=\frac{1}{W}\left(\int_{0}^{p_{0}} \overline{q \hat{u}} \frac{d p}{g}+\int_{0}^{p_{0}} \overline{q^{\prime} \hat{u^{\prime}}} \frac{d p}{g}\right) \\
V=\frac{1}{W}\left(\int_{0}^{p_{0}} \overline{q \hat{v}} \frac{d p}{g}+\int_{0}^{p_{0}} \overline{q^{\prime} \hat{v}^{\prime}} \frac{d p}{g}\right)
\end{gathered}
$$

In Eq. $2, \mathrm{~W}$ is the amount of precipitable water contained in an air column of unit area; $\bar{q}, q^{\prime}, \overline{\hat{u}}, \hat{u^{\prime}}, \overline{\hat{v}}$ and $\hat{v}^{\prime}$ are the temporal mean and the transient eddy values for specific humidity and for zonal and meridional wind components, 
respectively; $\mathrm{E}$ is evaporation; and $\mathrm{P}$ is precipitation. $\mathrm{U}$ (Eq. 3) and $\mathrm{V}$ (Eq. 4) are the effective zonal and meridional wind components, respectively. In all these equations, $\mathrm{g}$ is the acceleration due to the gravity force $\left(9.8 \mathrm{~m} \mathrm{~s}^{-2}\right)$.

Dominguez et al (2006) found that the atmospheric humidity fraction (R) collected by an air parcel along its trajectory between times $\tau^{\prime}=0$ and $\tau^{\prime}=\tau$ can be expressed as follows:

$$
R(\chi, \xi, \tau)=1-\exp \left[-\int_{0}^{\tau} \frac{E\left(\chi^{\prime}, \xi^{\prime}, \tau^{\prime}\right)}{W\left(\chi^{\prime}, \xi^{\prime}, \tau^{\prime}\right)} d \tau^{\prime}\right]
$$

Based on Eq. 5, Martínez and Dominguez (2014) developed a method to identify the contributions from each source region to a given sink region. It allows decomposing the trajectory of the plot when it reaches the sink region to identify in which regions the humidity of each part of the trajectory was generated. This method also allows quantifying the contribution of the same target region to its own humidity (i.e. moisture recycled).

We analyzed the climatological interannual variability of water vapor transport in NOSA associated to EN and LN events. We used atmospheric sub-daily data from the ERA5 reanalysis (Hersbach et al, 2020), at a resolution of $0.5^{\circ}$ for the period 1980-2019 (see Table 1) in the area between latitudes $20^{\circ} \mathrm{S}-19^{\circ} \mathrm{N}$ and longitudes $99^{\circ} \mathrm{W}-10.5^{\circ} \mathrm{W}$, as shown in Fig. 1 .

Table 1 Variables obtained from the ERA5 reanalysis to be used in the DRM

\begin{tabular}{ll}
\hline Variable & Time (hour) \\
\hline Evaporation & $00: 00,12: 00$ \\
Total precipitation & $00: 00,12: 00$ \\
Vertically-integrated water vapor & $00: 00,06: 00,12: 00,18: 00$ \\
Vertical integral of eastward water vapor & $00: 00,06: 00,12: 00,18: 00$ \\
Vertical integral of northward water vapor & $00: 00,06: 00,12: 00,18: 00$ \\
\hline
\end{tabular}




\subsection{Thermodynamic indices}

Additional to the atmospheric moisture transport estimates, we analyzed thermodynamic indices related to precipitation occurrence. Particularly, we considered the following variables from the ERA5 reanalysis, in accordance to Chen et al (2017):

- Convective Available Potential Energy (CAPE): it is an indicator of the instability (or stability) of the atmosphere. This index can be used to assess the potential for the development of convection, which can lead to precipitation, but it is not the only condition for precipitation to occur. Large positive values of CAPE indicate that an air parcel would be much warmer than its surrounding environment, very buoyant, suggesting great potential for severe weather (Gizaw et al, 2021).

- Convective Inhibition (CIN): in counterpart to CAPE, CIN is a measure of the amount of energy required for convection to occur. High values of this parameter indicate that deep and moist convection is unlikely to occur even if CAPE is large. Therefore, these two indices are complementary (Gizaw et al, 2021).

- Lifting Condensation Level (LCL): it is the height in the atmosphere at which the Relative Humidity $(\mathrm{RH})$ of an air parcel reaches $100 \%$ when it is cooled by dry adiabatic lifting from the surface. It is an estimation of the convective cloud-base height (Shi et al, 2021). In general, high cloud bases over the tropics indicate hot dry land surfaces.

- Low-level Relative Humidity (RH): humidity at low levels is important for convective initiation (Todd et al, 2018). Here, we used data of low-level $\mathrm{RH}$ as an average over the 1000-850 hPa layer.

For these variables, we considered monthly averages at two different hours a day: 06 UTC and 18 UTC, which represents NOSA's nighttime (01:00 LT) 
and daytime (13:00 LT), respectively, in order to analyze the diurnal cycle in these thermodynamic indices.

\subsection{Regional Hadley cell}

Finally, we considered the response of the regional Hadley cell in tropical South America to ENSO events. For this, we followed the approach formulated by Zhang and Wang (2013) to calculate a regional mass-stream function $(\Psi)$ without violating the principle of negligible net transport of zonal mass. This approach uses the meridional component of the irrotational flow, which contributes to the vertical motion in the north-south circulation represented by the Hadley cell. We calculated the meridional mass-stream function of the regional Hadley circulation over tropical South America, as shown by the Eq. 6 .

$$
\Psi=\frac{2 \pi \cos (\phi)}{g} \int_{0}^{p}\left[v_{I R}\right] d P
$$

Where $\phi$ is the latitude and $v_{I R}$ is the irrotational component of the meridional wind averaged for longitudes $70^{\circ} \mathrm{W}-50^{\circ} \mathrm{W}$. Similar to the thermodynamic indices described in subsection 2.4, we obtained the monthly wind fields to compute the irrotational component of the meridional wind from the ERA5 reanalysis at $06 \mathrm{UTC}$ and at $18 \mathrm{UTC}$. 


\section{Results}

\subsection{Atmospheric moisture contributions to NOSA during ENSO events}

Fig. 2 shows the annual cycle of precipitable water $(\mathrm{PW})$ and precipitation that are contributed from all considered sources in Fig. 1 to NOSA during EN and LN events. From February to July, we see more contribution of PW during EN, whereas the contribution from August to January is approximately equal in both EN and LN events. However, this contribution in PW does not correspond to the contribution in precipitation. In general, we see higher contribution in precipitation to NOSA during LN events. Before going deeper into the different responses in PW and precipitation, we quantified the changes in atmospheric moisture advection and recycling within the regions considered during both EN and LN events.
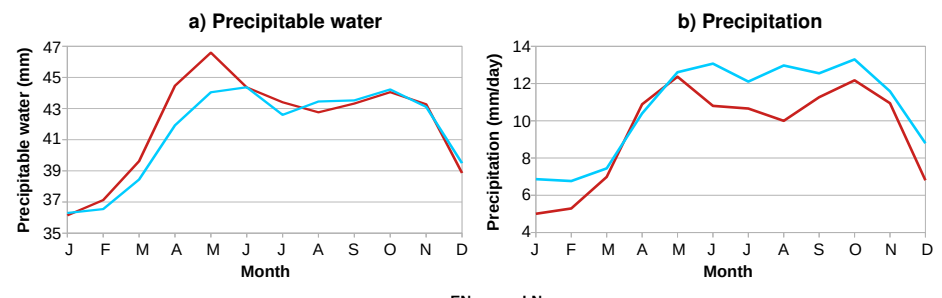

-EN - LN

Fig. 2 Total contributions of a) PW and b) precipitation to NOSA during EN (red) and LN (blue) events

Figures 3 to 6 show the difference in atmospheric moisture transport (colors) and vertically-integrated moisture flux (VIMF; vectors) for each season: December-February (DJF), March-May (MAM), June-August (JJA) and September-November (SON), respectively. The climatological EN and LN composites for VIMF are shown in the Appendix A in Fig. A1. Fig. 3 reveals 

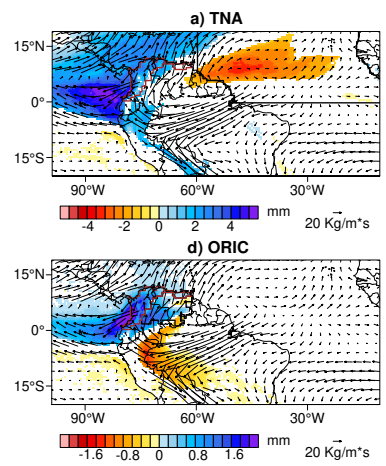

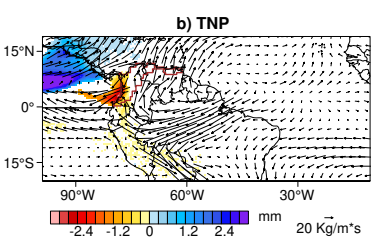
e) NOSA

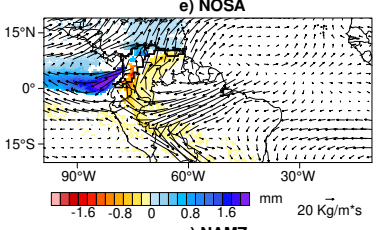

g) NAMZ

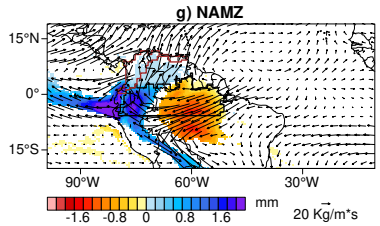

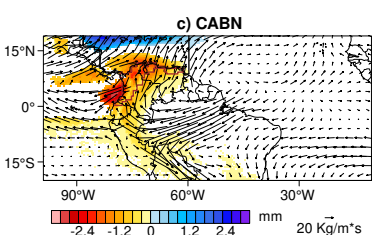
f) GUYN

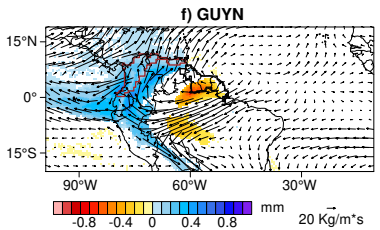

Fig. 3 Differences in atmospheric moisture contribution to NOSA (brown line) between EN and LN events during the DJF season from the sources (black line) a) TNA, b) TNP, c) CABN, d) ORIC, e) NOSA, f) GUYN and g) NAMZ. Vectors represent the difference in VIMF

For MAM, Fig. 4 shows in general more number of sources contributing in moisture to NOSA during EN events, which coincides with Fig. 2. Only CABN contributes less during EN than during LN events. During this season, we do not see a substantial difference in VIMF vectors over the NOSA subregion. 

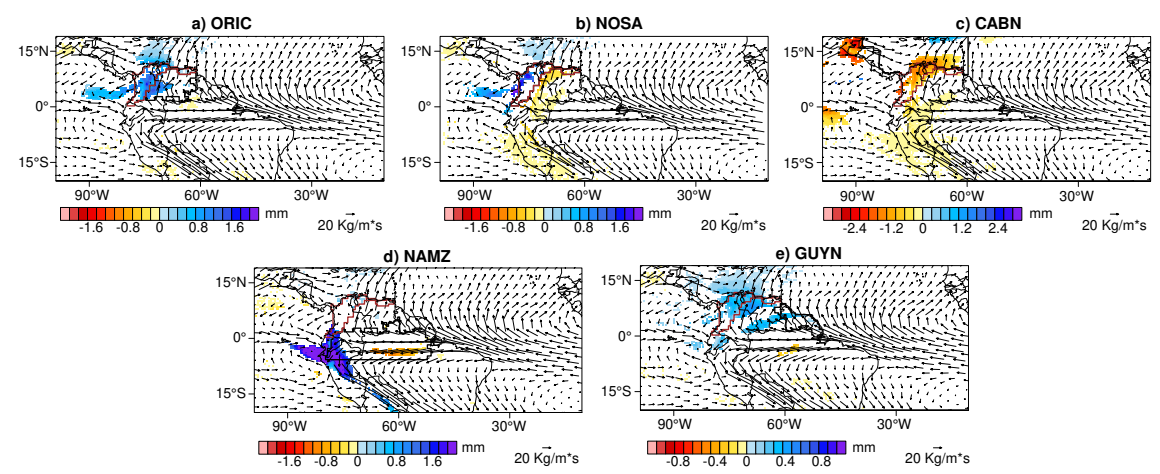

Fig. 4 Differences in atmospheric moisture contribution to NOSA (brown line) between EN and LN events during the MAM season from the sources (black line) a) ORIC, b) NOSA, c) CABN, d) NAMZ and d) GUYN. Vectors represent the difference in VIMF

During JJA, we see significant changes in moisture contribution from the regions shown in Fig. 5. TNA and GUYN are the only sources that contribute more moisture to NOSA during EN events. CABN, NAMZ and Southern Amazon (SAMZ) contribute less during EN. The moisture recycling in NOSA is also less during EN. VIMF vectors over Central America (CAM) during this season are strengthened in $\mathrm{EN}$ in relation to LN, and this factor endorses the westward moisture advection. These positive and negative contributions are of similar magnitude and thus they compensate, leaving a similar amount of atmospheric moisture over NOSA, as observed from Fig. 2.

Finally, for SON we mostly see less atmospheric moisture contributions to NOSA from the considered regions (Fig. 6). Only TNA contributes more moisture during EN than during LN. This is also linked to a weaker low-level jet over western Colombia, known as the Choco Jet, as discussed in Gallego et al (2019). Similar to what happens during JJA (Fig. 5), VIMF vectors over CAM are strengthened during EN, favouring the atmospheric moisture advection towards more western regions. 


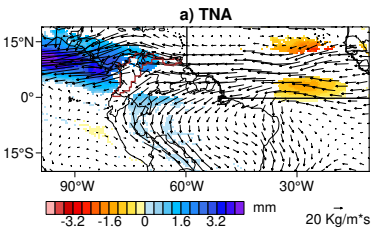

d) NAMZ

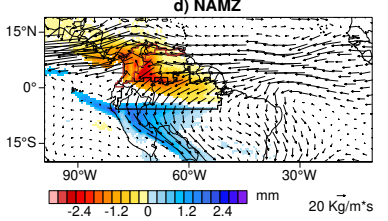

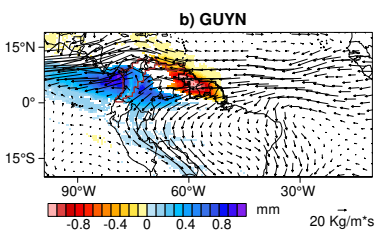

e) SAMZ

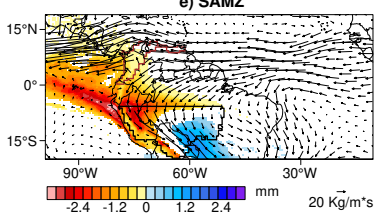

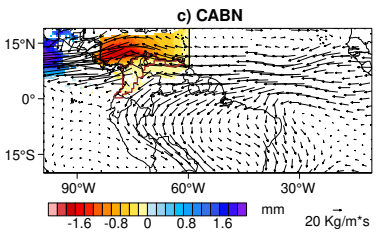

f) NOSA

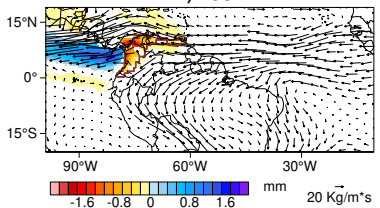

Fig. 5 Differences in atmospheric moisture contribution to NOSA (brown line) between EN and LN events during the JJA season from the sources (black line) a) TNA, b) GUYN, c) CABN, d) NAMZ, e) SAMZ and f) NOSA. Vectors represent the difference in VIMF
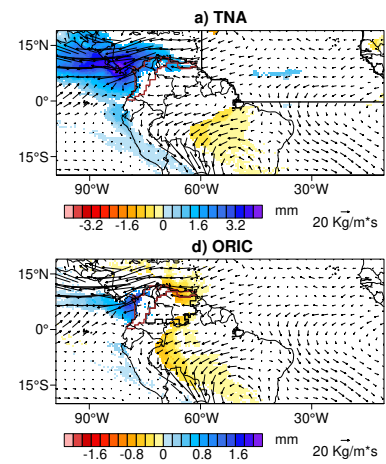

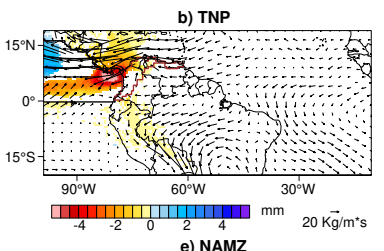

e) NAMZ

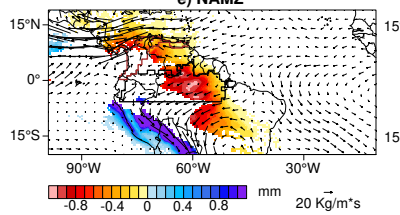

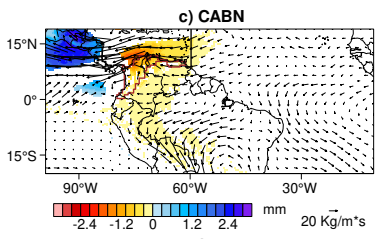

f) SAMZ

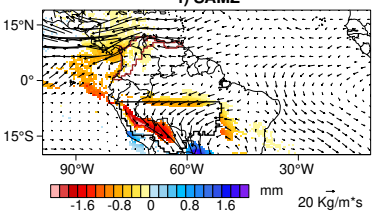

Fig. 6 Differences in atmospheric moisture contribution to NOSA (brown line) between EN and LN events during the SON season from the sources (black line) a) TNA, b) TNP, c) CABN, d) ORIC, e) NAMZ and f) SAMZ. Vectors represent the difference in VIMF

The percentage change in moisture contribution to NOSA from the sources considered in Figures 3 to 6 during LN relative to EN events is shown in Table 2. The most noteworthy changes are from TNP, GUYN and SAMZ, but these sources only contribute to NOSA approximately in $6 \%$ of the total atmospheric moisture, and therefore changes in these sources are small in absolute terms. Changes from TNA and NOSA are more meaningful because these sources contribute in approximately $45 \%$ of the total moisture in NOSA. Changes in CABN, ORIC and NAMZ are also important because they contribute in $19 \%$ 
to the total moisture (Arias et al, 2015). MAM is the season with the most remarkable change in PW, as seen also in Fig. 2a.

Table 2 Fraction (in \%) of moisture contribution to NOSA during LN events relative to EN events Blue (red) indicates increased (decreased) contribution.

\begin{tabular}{cllll}
\hline & DJF & MAM & JJA & SON \\
\hline TNP & 224.37 & 122.22 & 326.17 & 153.27 \\
TNA & 88.74 & 99.98 & 90.17 & 89.37 \\
CABN & 147.18 & 159.08 & 138.78 & 137.76 \\
NOSA & 102.22 & 94.76 & 118.07 & 101.08 \\
ORIC & 68.27 & 81.29 & 99.22 & 90.41 \\
GUYN & 40.81 & 72.32 & 82.52 & 91.88 \\
NAMZ & 69.42 & 72.11 & 130.57 & 112.47 \\
SAMZ & 434.39 & 146.79 & 437.85 & 198.48 \\
Total & 100.16 & 95.28 & 99.93 & 100.16 \\
\hline
\end{tabular}

Now that we have a clearer idea of the change in atmospheric moisture sources to NOSA during EN and LN events for all the seasons, we need to understand the counter-intuitive response of precipitation to the available PW. What does happen with the extra humidity from February to June in the atmosphere during EN? Why does it not precipitate? Which mechanisms favor the precipitation during LN from May to March? We tried to solve these questions from a thermodynamic perspective, quantifying the values of the indices described in subsection 2.4 and the regional Hadley cell, as introduced in subsection 2.5 .

\subsection{Thermodynamic indices during ENSO events}

To answer the questions above, we first looked at some thermodynamic conditions (indices) necessary for precipitation to occur, as described in subsection 
2.4. Although Figures 7-10 show the composites of the considered variables over the entire domain, we focused only on their values over NOSA during nighttime (06 UTC) and daytime (18 UTC).

Large values of CAPE are often associated with precipitation, provided that convection takes place and the release of CAPE happens. Fig. 7 shows the differences in CAPE composites between EN and LN events. In general, CAPE is higher over NOSA during EN than during LN events for all seasons, specially at nighttime. This index suggests that precipitation would be more likely to occur during EN, which is not what we observe from the response of precipitation in Fig. 2b. However, it is necessary to consider other indices in order to evaluate the occurrence of precipitation. Furthermore, given the complex topography of NOSA and the observed diurnal cycle, precipitation maximum is equally likely to occur during the afternoon and midnight (Poveda et al, 2005).
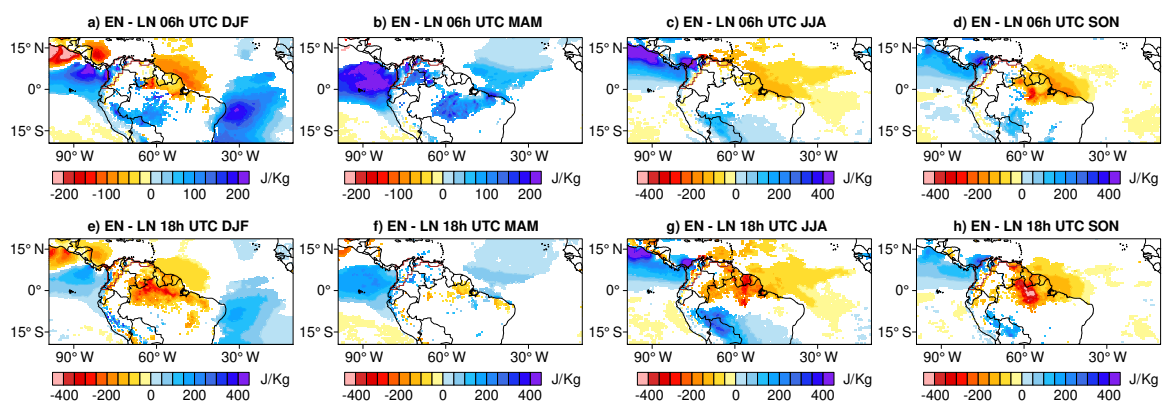

Fig. 7 Differences in CAPE between EN and LN events during seasons at a)-d) 06h UTC and e)-h) 18h UTC

However, in many situations CAPE cannot be released unless CIN has a small value (Markowski and Richardson, 2010). High values of CIN represent the amount of energy that is still required for the development of convective systems and therefore suggest the non-occurrence of precipitation. In Fig. 8 we 


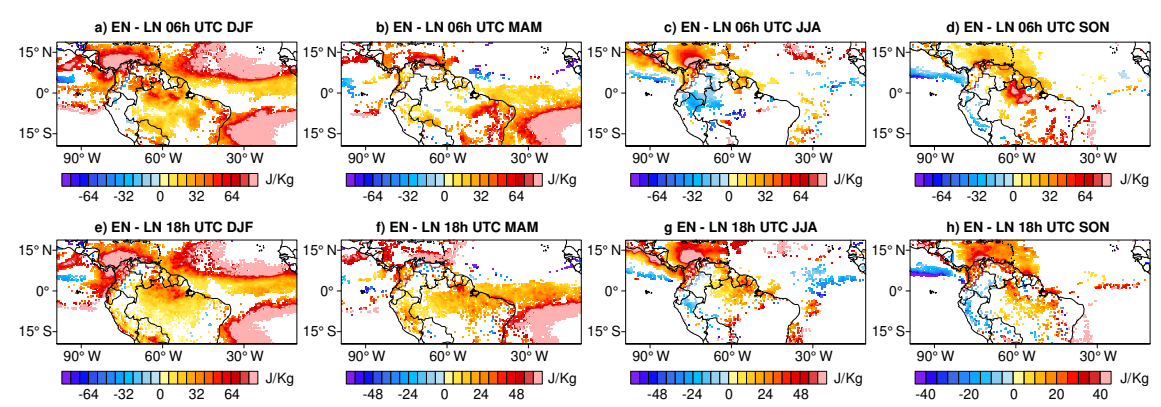

Fig. 8 Differences in CIN between EN and LN events during seasons at a)-d) 06h UTC and e)-h) 18h UTC

see high positive values of CIN across NOSA during all the seasons, specially at daytime (18 UTC) for the EN-LN composites. This pattern agrees with: (i) the non-occurrence of precipitation for EN events during the first semester of the year, in which there is more humidity in the atmosphere, and (ii) the favouring of precipitation during the second semester of the year, in which humidity over NOSA in both EN and LN events is more similar, as observed from Fig. 2a.

A third considered thermodynamic index is the LCL. High values of this index indicate high altitude of cloud-base and in tropical regions this suggests hot and dry surface conditions. Fig. 9 shows that cloud-base during EN events are higher than during LN events. MAM was the only season that did not show significant differences for this index between the two ENSO phases, but also this is the season when there are small differences in terms of precipitation between both EN and LN (Fig. 2b). The greatest differences in LCL are found during DJF and JJA, when the differences in precipitation are also the greatest. 

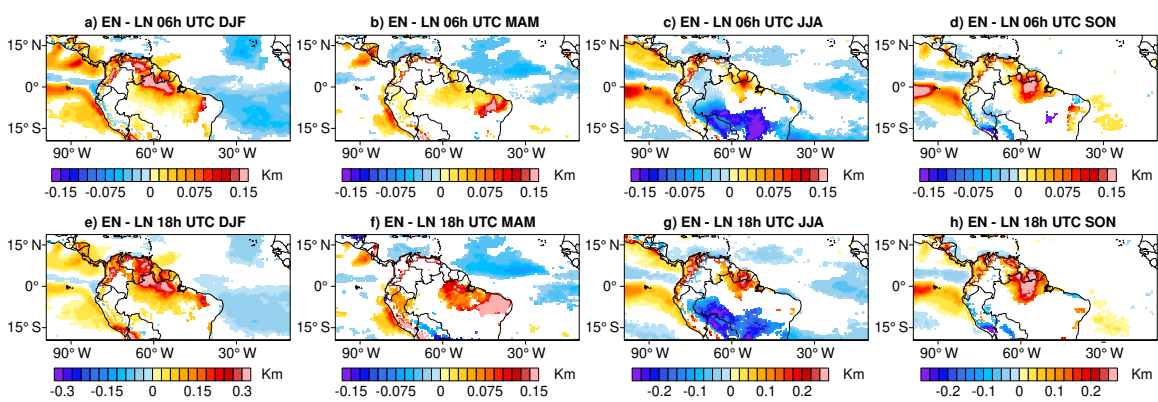

Fig. 9 Differences in LCL between EN and LN events during seasons at a)-d) 06h UTC and e)-h) 18h UTC

The final thermodynamic index considered is the low-level $\mathrm{RH}$ (the $\mathrm{RH}$ contained in the atmospheric layer between 1000 and $850 \mathrm{hPa}$; Fig. 10). This index is particularly important during DJF, with less RH humidity during EN than during LN. Even though there is more atmospheric humidity available in this season during EN events (Fig. 2a), the atmosphere is warmer and therefore the RH can be lower, inhibiting the occurrence of condensation and precipitation. In particular, $\mathrm{RH}$ has been investigated in Todd et al (2018), who found a strong correlation between $\mathrm{RH}$ and precipitation shifts during ENSO events, highlighting the importance of this variable as a feature for predicting precipitation shifts in modeled ENSO events.
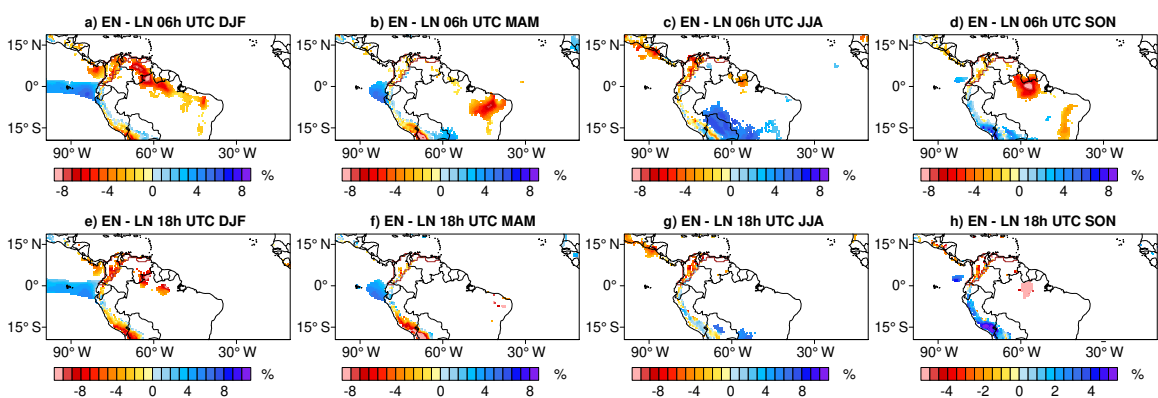

Fig. 10 Differences in low-level RH between EN and LN events during seasons at a)-d) 06h UTC and e)-h) 18h UTC 


\subsection{Regional Hadley cell during ENSO events}

To support the findings discussed in subsection 3.2, we also looked at the response of the regional Hadley circulation over NOSA to the ENSO phases. Fig. 11 shows the mean vertical motion at longitudes that cover the NOSA subregion $\left(70^{\circ} \mathrm{W}-50^{\circ} \mathrm{W}\right)$. The ascending branch of the Hadley cell is located over the latitudes of the summer hemisphere. The ascending motion favours the development of convective systems and therefore the occurrence of precipitation, whereas the descending motion inhibits precipitation. In the first and third columns of Fig. 11, we can see how this ascending branch shifts from one to another side of the Equator between seasons, being around $10^{\circ} \mathrm{S}$ during DJF (austral summer) and around $8^{\circ} \mathrm{N}$ during JJA (boreal summer). During the transition seasons (MAM and SON), the ascending branch is not clear and spans over more latitudes. The second and fourth columns in Fig. 11 show the differences in this vertical motion between EN and LN events.

Overall, we see a weakening in the ascending motion during EN events and a strengthening in the descending motion during LN events, favouring the inhibition of precipitation during EN, as first discussed by Kousky et al (1984) and Ropelewski and Halpert (1987). This weakening (strengthening) of the ascending (descending) motion during EN is also consistent with the results from Martín-Gómez et al (2020) and Sátori et al (2009). The weakening of the ascending motion is particularly strong during DJF and JJA, thus even though there is slightly more PW in the atmosphere for both seasons during EN (Fig. 2a), the ascending motion is inhibited and therefore the development of convective systems. The strengthened response in precipitation during LN shows that the also strengthened ascending motion in this phase compensates a lower available humidity. 
20 ENSO influence over Northern South America

Finally, for the rainy seasons in NOSA (MAM and SON), we see that the weakening of the ascending motion during EN accounts for the difference in precipitation with respect to LN. For MAM, we see the largest differences in PW over NOSA between both ENSO phases (PW being greater during EN), but the increased ascending motion during LN makes precipitation values very similar to that of EN. For SON, even though the amount of PW is very similar in both phases, precipitation is strengthened during LN (Fig. 2b) due to an enhanced ascending motion. 

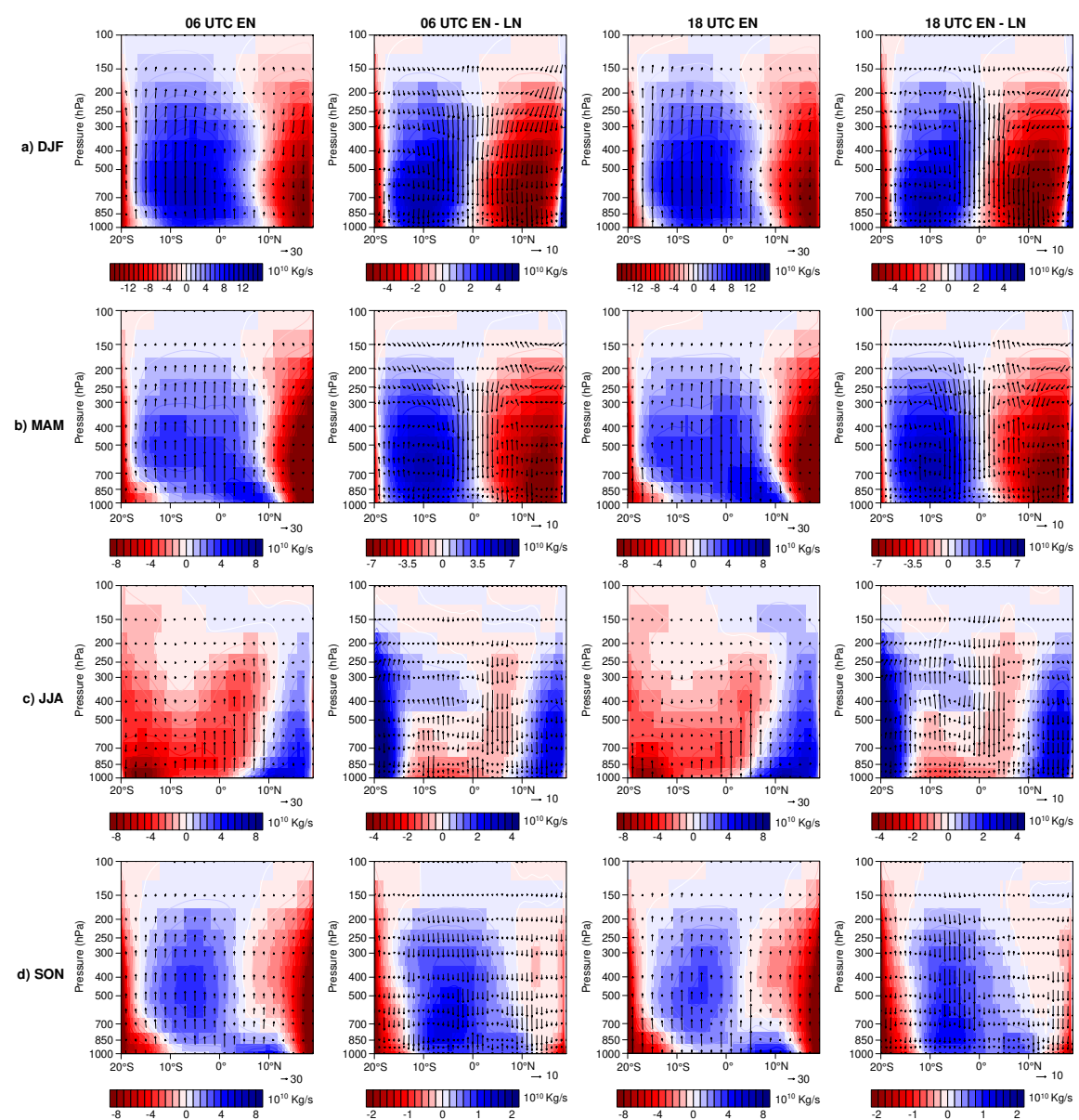

Fig. 11 Vertical cross-sections of the regional mass-stream function (contours) averaged over $70^{\circ} \mathrm{W}-50^{\circ} \mathrm{W}$ for a) DJF, b) MAM, c) JJA and d) SON for EN events (first and third columns) and for the difference between EN and LN events (second and fourth columns). Vectors represent the divergent component of the meridional wind (in $\mathrm{m} / \mathrm{s}$ ) and the vertical pressure velocity (in $10^{3} \mathrm{hPa} / \mathrm{s}$ )

\section{Discussion and conclusions}

The aim for this study was to investigate the following question: how is the

structure of the atmospheric moisture sources of Northern South America 
(NOSA) during El Niño-Southern Oscillation (ENSO) events? Interestingly, the answer led us also to find that during about half of an El Niño (EN) year there is more precipitable water (PW) than during a La Niña (LN) year, despite the fact that rain can be greater during the latter. Besides the change in the moisture sources, we also explored the role of plausible dynamic and thermodynamic mechanisms for such changes. Our findings are summarized in Fig. 12.
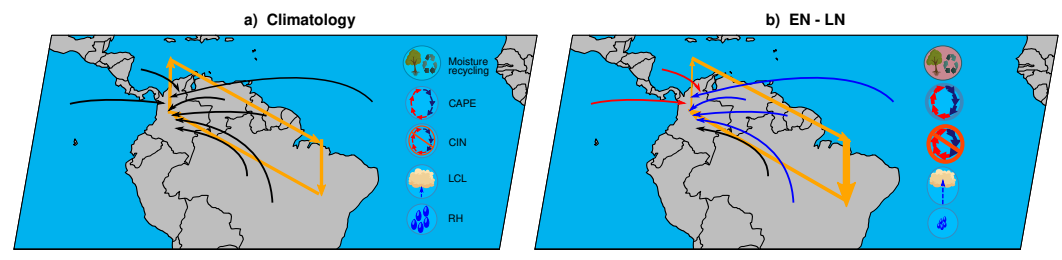

Fig. 12 Schematic of the main changes in atmospheric moisture transport, regional circulation and thermodynamic indices over NOSA in association with ENSO events for a) Climatology and b) EN-LN. Black arrows in a) indicate atmospheric moisture transport from the different sources to NOSA, while in b) red (blue) arrows indicate less (more) moisture transport and black arrows indicate no virtual change. Yellow arrows represent the regional Hadley cell. The other symbols (moisture recycling and thermodynamic indices) are defined in a). An increase (decrease) in the size of the symbols indicates a strengthening (weakening) during EN events in comparison to LN events. Red moisture recycling symbol in b) indicates less atmospheric moisture recycling during EN

Using the Dynamic Recycling Model (DRM), we computed the trajectories of PW over the region. From February to July, we saw more contribution from different sources during EN than during LN events, whilst for the remaining months the contribution is similar between both phases. Fig. 12 shows which moisture trajectories increase (thick black arrows) and which trajectories decrease (thin black arrows) in EN events. Only the Caribbean (CABN) and Tropical North Pacific (TNP) sources reduce their contribution to NOSA 
during EN. The Orinoco basin (ORIC), Guyanas (GUYN), Southern Amazon (SAMZ) and Tropical North Atlantic (TNA) increase their contribution. The moisture recycling (represented by the red circle with the tree and the recycling symbol) in NOSA is lower during EN events.

The response of precipitation to the change in these trajectories of $\mathrm{PW}$ and moisture recycling during ENSO is not-linear. The amount of precipitation largely depends in the available PW (Chen et al, 2017), but also on local conditions such as atmospheric stability, advection rate and regional circulation patterns. Accordingly, we also looked at the response of some thermodynamic indices and the atmospheric regional circulation to both ENSO phases. These variables strongly influence the occurrence of precipitation as seen in Chen et al (2017) and Liu et al (2020).

To account for the thermodynamics, we considered: Convective Available Potential Energy (CAPE), Convective Inhibition (CIN), Lifting Condensation Level (LCL) and low-level Relative Humidity (RH). The last three indices responded properly to the studied role of precipitation during the ENSO events. From a thermodynamic perspective, precipitation is less favored during EN events because: (i) there is more energy required for convection to occur (higher CIN), (ii) the air parcels reach saturation at higher altitudes (higher LCL) and (iii) the lowest levels in the atmosphere have less RH, which makes the condensation process more difficult. Only CAPE showed counter-intuitive values to this reasoning but its analysis needs to be taken along with the other indices. Moreover, during sunny days with low cloud coverage, such as those during EN (Dommenget, 2010) over the region, the near-surface temperature is higher, which enhances potential temperature of air parcels and therefore enhances CAPE. 
As a last mechanism to explain precipitation occurrence during EN and LN, we studied the response of the regional Hadley cell to the these phases. Similar to what we found with the thermodynamic indices, the Hadley cell also supports the favouring of precipitation during LN. For all the seasons we saw a weaker (stronger) ascending branch during EN (LN) events over NOSA, which confines (enhances) the upward motion of air masses and the condensation process over the region. This result also reinforces the findings by Ropelewski and Halpert (1987), who highlighted the subsidence over NOSA due to a westward displacement of the Walker circulation during EN. In Fig. 12, the Hadley cell is represented by the yellow arrows, and the upward branch is thinner because it is weakened during EN.

According to the water budget for the atmosphere, the precipitation rate is related to changes in $\mathrm{PW}$, not just to its absolute value. Therefore, a large value of $\mathrm{PW}$ could be associated with little precipitation provided that $\mathrm{PW}$ does not change too much on a given period of time (e.g. no increase in PW with time). In this study, larger values of PW during EN events might be possible if a weak convergence of atmospheric moisture leads to a slow accumulation of moisture and lower precipitation rates. In contrast, during LN events, there is an increase in precipitation for the region of interest, despite the lower values of PW (compared to EN). From an atmospheric moisture point of view, this can be possible with enhanced convergence of moisture providing larger rates of change of PW. The extra precipitation would be then associated with asymmetric changes in regional circulation that intensify moisture convergence, and favors thermodynamic environments for unstable conditions. Finally, these asymmetric changes in circulation are linked to an enhancement of certain moisture sources during LN, including those from the Pacific ocean (with respect to to EN), while during EN the other sources dominate (from the 
Atlantic ocean and from continental sources like ORIC and Northern Amazon, although this last source contributes more in June-July-August for EN than during LN events).

Thermodynamics and regional circulation play a key role in the response of precipitation over NOSA during EN and LN events, even more than the moisture content in the atmosphere. For example, during the 2015 flash flood event in La Liboriana basin in Salgar, Colombia (Hoyos et al, 2019a), the regional circulation and the atmospheric convection enhanced the orographicorigin rainfall episode that triggered the extreme flood, even under negative precipitation anomalies during an EN year. There are other extreme cases in which the content of water vapor can dominate the response in precipitation during LN events, as seen in Arias et al (2015), who found that the anomalous wet season in NOSA during 2010-2012 was largely controlled by extra moisture contributions from the adjacent oceans. Nevertheless, this was a very unique LN event. In this study, we considered the average of all EN and LN events during the period 1980-2019, from which we could see that thermodynamics and regional circulation had a dominant role in the occurrence of precipitation. Changes in the atmosphere-ocean coupling due to ENSO variability modify air temperature over land and therefore the atmospheric stability, which is essential for precipitation to occur.

Previous studies have shown that NOSA is particularly sensitive to the influence of ENSO (Poveda and Mesa, 1996; Poveda et al, 2006; Hoyos et al, 2019b; Salas et al, 2020; Arias et al, 2021). In general, EN events induce reductions in precipitation and runoff in the region (Córdoba-Machado et al, 2015; Serna et al, 2018; Canchala et al, 2020) while LN events are associated with the opposite (Hoyos et al, 2013; Arias et al, 2015). This work provides further evidence of the key role played by regional atmospheric circulation and 
thermodynamics in the mechanisms for ENSO influence on precipitation in this region.

Acknowledgments. This work was founded by Universidad de Antioquia through the Grant CODI PRG2017-16264, and by MINCIENCIAS through the grant No. 80740-490-2020.

\section{Statements and declarations.}

- Competing interests

The authors declare that there are no conflicts of interest.

Data availability. The datasets generated and analysed during the current study are available from the corresponding author on reasonable request. 


\section{${ }_{472}$ Appendix A}

Table A1 Classification of seasons in El Niño (red) and La Niña (blue) events

\begin{tabular}{|c|c|c|c|}
\hline DJF & MAM & JJA & SON \\
\hline $1982-1983$ & 1982 & 1982 & 1982 \\
\hline 1983-1984 & 1983 & 1985 & 1983 \\
\hline 1984-1985 & 1985 & 1987 & 1984 \\
\hline 1986-1987 & 1987 & 1988 & 1986 \\
\hline $1987-1988$ & 1989 & 1991 & 1987 \\
\hline 1988-1989 & 1992 & 1997 & 1988 \\
\hline 1991-1992 & 1998 & 1998 & 1991 \\
\hline 1994-1995 & 1999 & 1999 & 1994 \\
\hline 1995-1996 & 2000 & 2000 & 1995 \\
\hline 1997-1998 & 2008 & 2002 & 1997 \\
\hline 1998-1999 & 2011 & 2004 & 1998 \\
\hline 1999-2000 & 2012 & 2007 & 1999 \\
\hline 2000-2001 & 2015 & 2009 & 2000 \\
\hline $2002-2003$ & 2016 & 2010 & 2002 \\
\hline $2004-2005$ & 2018 & 2011 & 2004 \\
\hline 2005-2006 & 2019 & 2015 & 2006 \\
\hline $2006-2007$ & & & 2007 \\
\hline 2007-2008 & & & 2009 \\
\hline 2008-2009 & & & 2010 \\
\hline 2009-2010 & & & 2011 \\
\hline 2010-2011 & & & 2014 \\
\hline 2011-2012 & & & 2015 \\
\hline $2014-2015$ & & & 2016 \\
\hline $2015-2016$ & & & 2017 \\
\hline $2017-2018$ & & & 2018 \\
\hline 2018-2019 & & & \\
\hline
\end{tabular}




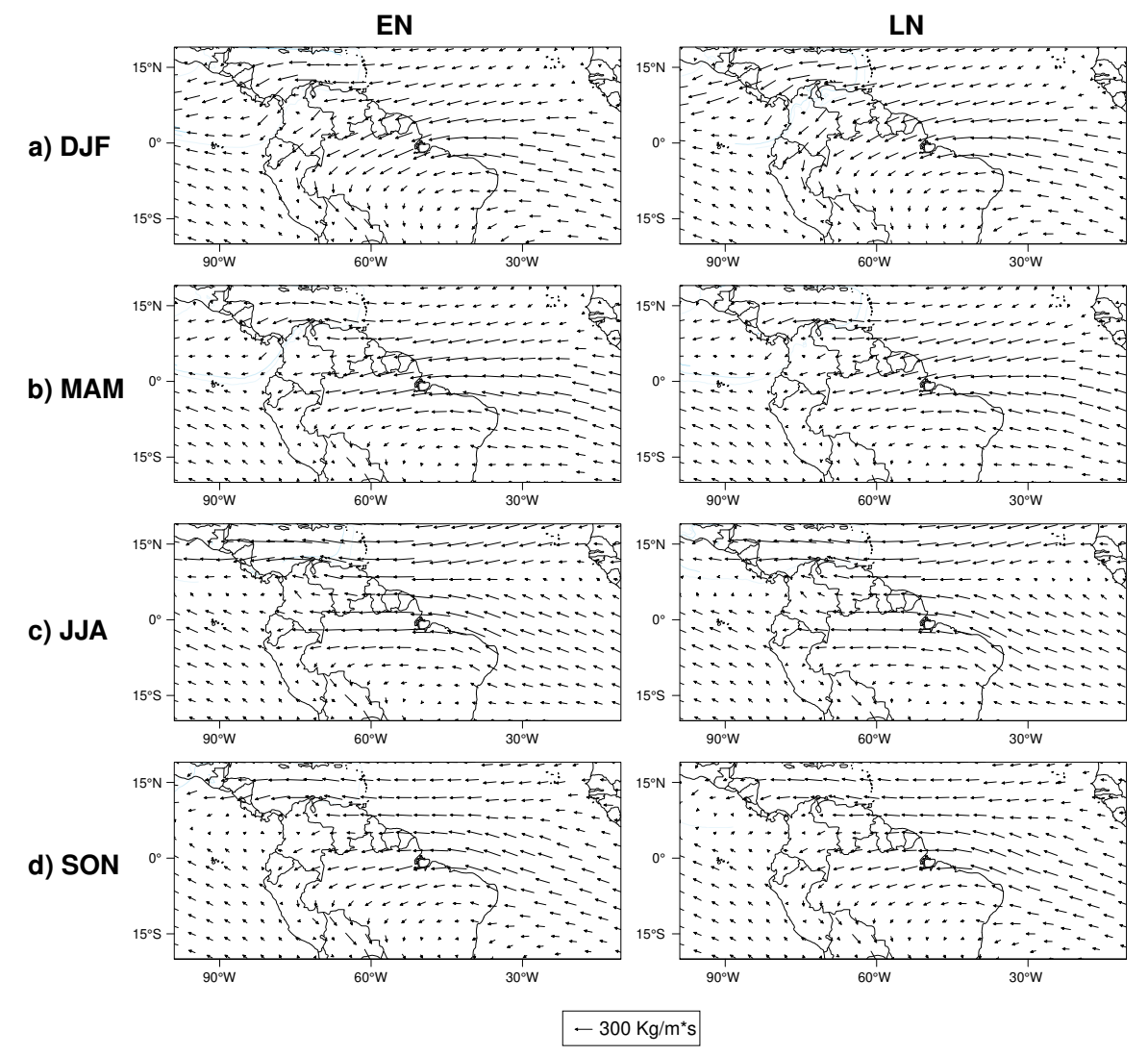

Fig. A1 Vertical Integral Moisture Flux (VIMF) vectors for El Niño (left column) and La Niña (right column)

\section{References}

Agudelo J, Arias PA, Vieira SC, et al (2019) Influence of longer dry seasons in the southern Amazon on patterns of water vapor transport over northern South America and the Caribbean. Climate Dynamics 52(5-6):2647-2665. https://doi.org/10.1007/s00382-018-4285-1 
Arias PA, Martínez JA, Vieira SC (2015) Moisture sources to the 2010-2012 anomalous wet season in northern South America. Climate dynamics 45(910):2861-2884. https://doi.org/10.1007/s00382-015-2511-7

Arias PA, Garreaud R, Poveda G, et al (2021) Hydroclimate of the Andes part ii: hydroclimate variability and sub-continental patterns. Frontiers in Earth Science 8:666. https://doi.org/10.3389/feart.2020.505467

Bayr T, Drews A, Latif M, et al (2021) The interplay of thermodynamics and ocean dynamics during ENSO growth phase. Climate Dynamics 56(5). https://doi.org/10.1007/s00382-020-05552-4

Bolaños S, Salazar JF, Betancur T, et al (2021) GRACE reveals depletion of water storage in northwestern South America between ENSO extremes. Journal of Hydrology 596:125,687. https://doi.org/10.1016/j.jhydrol.2020. 125687

Cai W, McPhaden MJ, Grimm AM, et al (2020) Climate impacts of the El Niño-Southern Oscillation on South America. Nature Reviews Earth \& Environment 1:215-231. https://doi.org/10.1038/s43017-020-0040-3

Canchala T, Loaiza Cerón W, Francés F, et al (2020) Streamflow variability in Colombian Pacific basins and their teleconnections with climate indices. Water 12(2). https://doi.org/10.3390/w12020526

Capotondi A, Wittenberg AT, Newman M, et al (2015) Understanding ENSO diversity. Bulletin of the American Meteorological Society 96(6):921-938. https://doi.org/10.1175/BAMS-D-13-00117.1

Castillo R, Nieto R, Drumond A, et al (2014) The role of the ENSO cycle in the modulation of moisture transport from major oceanic moisture 


\section{Springer Nature $2021 \mathrm{LAT}_{\mathrm{E}} \mathrm{X}$ template}

sources. Water Resources Research 50(2):1046-1058. https://doi.org/10. 1002/2013WR013900

Cerón WL, Kayano MT, Andreoli RV, et al (2021) Rainfall variability in southwestern Colombia: changes in ENSO-related features. Pure and Applied Geophysics 178:1087-1103. https://doi.org/10.1007/s00024-021-02673-7

Chen B, Liu C, Mapes BE (2017) Relationships between large precipitating systems and atmospheric factors at a grid scale. Journal of the Atmospheric Sciences 74(2):531-552. https://doi.org/10.1175/JAS-D-16-0049.1

Córdoba-Machado S, Palomino-Lemus R, Gámiz-Fortis SR, et al (2015) Assessing the impact of El Niño Modoki on seasonal precipitation in Colombia. Global and Planetary Change 124:41-61. https://doi.org/10.1016/j. gloplacha.2014.11.003

Dominguez F, Kumar P, Liang XZ, et al (2006) Impact of atmospheric moisture storage on precipitation recycling. Journal of Climate 19(8):1513-1530. https://doi.org/10.1175/JCLI3691.1

Dommenget D (2010) The slab ocean El Niño. Geophysical Research Letters 37(20). https://doi.org/10.1029/2010GL044888

Efron B (1992) Bootstrap methods: another look at the Jackknife, Springer New York, pp 569-593. https://doi.org/10.1214/aos/1176344552

Gallego D, García-Herrera R, Gómez-Delgado FDP, et al (2019) Tracking the moisture transport from the Pacific towards central and northern South America since the late 19th century. Earth System Dynamics 10(2):319-331. https://doi.org/10.5194/esd-10-319-2019 
Gizaw MS, Gan TY, Yang Y, et al (2021) Changes to the 1979-2013 summer Convective Available Potential Energy (CAPE) and extreme precipitation over North America. Physics and Chemistry of the Earth, Parts A/B/C 123:103,047. https://doi.org/10.1016/j.pce.2021.103047

Glantz MH, Ramirez IJ (2020) Reviewing the Oceanic Niño Index (ONI) to enhance societal readiness for El Niño's impacts. International Journal of Disaster Risk Science 11:394-403. https://doi.org/10.1007/ s13753-020-00275-w

Guo YP, Li JP (2016) Impact of ENSO events on the interannual variability of Hadley circulation extents in boreal winter. Advances in Climate Change Research 7(1-2):46-53. https://doi.org/10.1016/j.accre.2016.05.001

Hersbach H, Bell B, Berrisford P, et al (2020) The ERA5 global reanalysis. Quarterly Journal of the Royal Meteorological Society 146(730):1999-2049. https://doi.org/10.1002/qj.3803

Hoyos CD, Ceballos LI, Pérez-Carrasquilla JS, et al (2019a) Meteorological conditions leading to the 2015 Salgar flash flood: lessons for vulnerable regions in tropical complex terrain. Natural Hazards and Earth System Sciences 19(11):2635-2665. https://doi.org/10.5194/nhess-19-2635-2019

Hoyos I, Cañón-Barriga J, Arenas-Suárez T, et al (2019b) Variability of regional atmospheric moisture over northern South America: patterns and underlying phenomena. Climate Dynamics 52:893-911. https://doi.org/10. 1007/s00382-018-4172-9

Hoyos N, Escobar J, Restrepo J, et al (2013) Impact of the 2010-2011 La Niña phenomenon in Colombia, South America: the human toll of an 
extreme weather event. Applied Geography 39:16-25. https://doi.org/10. 1016/j.apgeog.2012.11.018

Kayano MT, Andreoli RV, Souza RAFd (2019) El Niño-Southern Oscillation related teleconnections over South America under distinct Atlantic Multidecadal Oscillation and Pacific Interdecadal Oscillation backgrounds: La Niña. International Journal of Climatology 39(3):1359-1372. https://doi. org/10.1002/joc.5886

Kim HM, Zhou Y, Alexander MA (2019) Changes in atmospheric rivers and moisture transport over the northeast Pacific and western North America in response to ENSO diversity. Climate Dynamics 52(12):7375-7388. https: //doi.org/10.1007/s00382-017-3598-9

Kousky VE, Kagano MT, Cavalcanti IFA (1984) A review of the Southern Oscillation: oceanic-atmospheric circulation changes and related rainfall anomalies. Tellus A 36A(5):490-504. https://doi.org/10.1111/j.1600-0870. 1984.tb00264.x

Lintner BR, Boos WR (2019) Using atmospheric energy transport to quantitatively constrain South Pacific Convergence Zone shifts during ENSO. Journal of Climate 32(6):1839 - 1855. https://doi.org/10.1175/JCLI-D-18-0151. 1

Liu N, Liu C, Chen B, et al (2020) What are the favorable large-scale environments for the highest-flash-rate thunderstorms on earth? Journal of the Atmospheric Sciences 77(5):1583-1612. https://doi.org/10.1175/ JAS-D-19-0235.1 
Llamedo P, Hierro R, de la Torre A, et al (2017) ENSO-related moisture and temperature anomalies over South America derived from GPS radio occultation profiles. International Journal of Climatology 37(1):268-275. https://doi.org/10.1002/joc.4702

Markowski P, Richardson Y (2010) Mesoscale meteorology in midlatitudes, vol 1. John Wiley \& Sons, https://doi.org/10.1002/9780470682104

Martín-Gómez V, Barreiro M, Losada T, et al (2020) Southern hemisphere circulation anomalies and impacts over subtropical South America due to different El Niño flavours. International Journal of Climatology 40(14):62016218. https://doi.org/10.1002/joc. 6577

Martínez JA, Dominguez F (2014) Sources of atmospheric moisture for the La Plata river basin. Journal of Climate 27(17):6737-6753. https://doi.org/10. 1175/JCLI-D-14-00022.1

Mesa-Sánchez OJ, Rojo-Hernández JD (2020) On the general circulation of the atmosphere around Colombia. RACCEFYN 44(172):857-875. https:// doi.org/10.18257/raccefyn.899

Morales JS, Arias PA, Martínez JA, et al (2021) The role of low-level circulation on water vapour transport to central and northern South America: insights from a 2D Lagrangian approach. International Journal of Climatology 41(S1):E2662-E2682. https://doi.org/10.1002/joc.6873

Poveda G, Mesa 1996) Las fases extremas del fenómeno ENSO (El Niño y la Niña) y su influencia sobre la hidrología de Colombia. Tecnología y Ciencias del Agua 11(1) 


\section{Springer Nature $2021 \mathrm{LAT}_{\mathrm{E}} \mathrm{X}$ template}

Poveda G, Mesa 1999) The low level westerly jet (Choco jet) and two other jets in Colombia: climatology and variability during ENSO phases. Rev Acad Colomb Cienc 23(89):517-528

Poveda G, Mesa (2000) On the existence of Lloró (the rainiest locality on earth): enhanced ocean-land-atmosphere interaction by a low-level jet. Geophysical Research Letters 27(11):1675-1678. https://doi.org/10.1029/ 1999GL006091

Poveda G, Mesa, Salazar LF, et al (2005) The diurnal cycle of precipitation in the tropical Andes of Colombia. Monthly Weather Review 133(1):228-240. https://doi.org/10.1175/MWR-2853.1

Poveda G, Waylen PR, Pulwarty RS (2006) Annual and inter-annual variability of the present climate in northern South America and southern Mesoamerica. Palaeogeography, Palaeoclimatology, Palaeoecology 234(1):327. https://doi.org/10.1016/j.palaeo.2005.10.031

Riemann-Campe K, Fraedrich K, Lunkeit F (2009) Global climatology of Convective Available Potential Energy (CAPE) and Convective Inhibition (CIN) in ERA-40 reanalysis. Atmospheric Research 93(1):534-545. https: //doi.org/10.1016/j.atmosres.2008.09.037

Rollings M, Merlis TM (2021) The observed relationship between Pacific SST variability and Hadley cell extent trends in reanalyses. Journal of Climate 34(7):2511 - 2527. https://doi.org/10.1175/JCLI-D-20-0410.1

Ropelewski CF, Halpert MS (1987) Global and regional scale precipitation patterns associated with the El Niño/Southern Oscillation. Monthly Weather Review 115(8):1606-1626. https://doi.org/10.1175/ 

1520-0493(1987)115<1606:GARSPP $>2.0 . \mathrm{CO} ; 2$

Ropelewski CF, Halpert MS (1989) Precipitation patterns associated with the high index phase of the Southern Oscillation. Journal of Climate 2(3):268284. https://doi.org/10.1175/1520-0442(1989)002〈0268:PPAWTH $\rangle 2.0 . C O ; 2$

Ruiz-Vásquez M, Arias PA, Martínez JA, et al (2020) Effects of Amazon basin deforestation on regional atmospheric circulation and water vapor transport towards tropical South America. Climate Dynamics 54(9):4169-4189. https: //doi.org/10.1007/s00382-020-05223-4

Salas HD, Poveda G, Mesa, et al (2020) Generalized synchronization between ENSO and hydrological variables in Colombia: a recurrence quantification approach. Frontiers in Applied Mathematics and Statistics 6:3. https://doi. org/10.3389/fams.2020.00003

Serna L, Arias PA, Vieira S (2018) Las corrientes superficiales de chorro del Chocó y el Caribe durante los eventos de El Niño y El Niño Modoki. Revista de la Academia Colombiana de Ciencias Exactas, Físicas y Naturales 42(165):410-421. https://doi.org/10.18257/raccefyn.705

Shi P, Lu H, Leung LR, et al (2021) Significant land contributions to interannual predictability of east Asian summer monsoon rainfall. Earth's Future 9(2). https://doi.org/10.1029/2020EF001762

Shimizu MH, Ambrizzi T, Liebmann B (2017) Extreme precipitation events and their relationship with ENSO and MJO phases over northern South America. International Journal of Climatology 37(6):2977-2989. https://doi. org/10.1002/joc.4893 
Sori R, Nieto R, Liberato M, et al (2021) Oceanic versus terrestrial origin of El

Niño Southern Oscillation-associated continental precipitation anomalies. Annals of the New York Academy of Sciences 1:1-13. https://doi.org/10. 1111/nyas. 14665

Sulca J, Takahashi K, Espinoza JC, et al (2018) Impacts of different ENSO flavors and tropical Pacific convection variability (ITCZ, SPCZ) on austral summer rainfall in South America, with a focus on Perú. International Journal of Climatology 38(1):420-435. https://doi.org/10.1002/joc.5185

Sátori G, Williams E, Lemperger I (2009) Variability of global lightning activity on the ENSO time scale. Atmospheric Research 91(2):500-507. https://doi.org/10.1016/j.atmosres.2008.06.014

Todd A, Collins M, Lambert FH, et al (2018) Diagnosing ENSO and global warming tropical precipitation shifts using surface relative humidity and temperature. Journal of Climate 31(4):1413 - 1433. https://doi.org/10. 1175/JCLI-D-17-0354.1

Wang C (2004) ENSO, Atlantic climate variability, and the Walker and Hadley circulations, Springer Netherlands, pp 173-202. https://doi.org/10.1007/ 978-1-4020-2944-8_7

Yan Y, Wu H, Gu G, et al (2020) Exploring the ENSO impact on basinscale floods using hydrological simulations and TRMM precipitation. Geophysical Research Letters 47(22):e2020GL089,476. https://doi.org/10.1029/ 2020GL089476

Ye B, Genio ADD, Lo KKW (1998) CAPE variations in the current climate and in a climate change. Journal of Climate 11(8):1997 - 2015. https://doi. 
Springer Nature 2021 LTEX template

ENSO influence over Northern South America org/10.1175/1520-0442(1998)011〈1997:CVITHCC $\rangle 2.0 . C O ; 2$

Zhang G, Wang Z (2013) Interannual variability of the Atlantic Hadley circulation in boreal summer and its impacts on tropical cyclone activity. Journal of Climate 26(21):8529-8544. https://doi.org/10.1175/JCLI-D-12-00802.1 